Check for updates

Cite this: Environ. Sci.: Processes Impacts, 2020, 22, 1566

Received 9th April 2020

Accepted 15th June 2020

DOI: $10.1039 / \mathrm{d} 0 \mathrm{em} 00160 \mathrm{k}$

rsc.li/espi

\section{The ecological half-life of radiocesium in surficial bottom sediments of five ponds in Fukushima based on in situ measurements with plastic scintillation fibers $\dagger$}

\author{
Estiner Walusungu Katengeza, (D) *a Yukihisa Sanada, ${ }^{\mathrm{b}}$ Kazuya Yoshimura, ${ }^{\mathrm{b}}$ \\ Kotaro Ochi ${ }^{\mathrm{b}}$ and Takeshi limoto ${ }^{\mathrm{a}}$
}

\begin{abstract}
Plastic scintillation fibers (PSFs) have been instrumental in in situ surface contamination surveys post the Fukushima Daichi Nuclear Power Plant accident. Their deployment to monitoring bottom sediments in aquatic environments provides the spatial extent of contamination over wide areas compared to discrete points as provided traditionally by sediment sampling. This study evaluated the wide area ecological halflife $\left(T_{\text {eco }}\right)$ of radiocesium concentration for surface sediments of five ponds in Fukushima using PSFs, monitoring data generated between 2013 and 2019. The least squares' regression method was employed to evaluate the $T_{\text {eco. }}$. Four ponds had a $T_{\text {eco }}$ ranging from $3.0 \pm 0.3$ years to $11.4 \pm 2.3$ years. A forestcatchment pond exhibited a relatively long $T_{\text {eco }}$ of $41.6 \pm 55$ years. Local variation in the $T_{\text {eco }}$ appears to be influenced by sedimentation as we demonstrated larger values for areas showing potential sedimentation in the forest catchment pond. This study demonstrates the importance of wide area in situ monitoring techniques, such as PSF, in providing an overview of the spatial-temporal trends of radiocesium in bottom sediments and confirms the importance of forests as secondary contaminant sources to their drainage.
\end{abstract}

Environmental significance

In aquatic environments, most radiocesium is bound to sediments. Characterizing radiocesium concentration in surface sediments is, therefore, critical for assessing the associated risk to the ecosystem. However, due to labor and cost associated with sediment underwater sampling and subsequent radioactivity analysis, spatial distribution studies/monitoring for radiocesium in the waterbed are limited. Consequently, long-term impacts are defined mainly for discrete points. In situ techniques may potentially solve this problem and this study employed plastic scintillation fibers to monitor wide areas of five agricultural ponds in Fukushima and subsequently evaluated the ecological half-life of radiocesium concentration in the surface sediments. This provides practical parameters for the impact of the radionuclide in these media and their surrounding catchment and drainage.

\section{Introduction}

Radiocesium, ${ }^{137} \mathrm{Cs}$ (half-life 30.2 years) and ${ }^{134} \mathrm{Cs}$ (half-life 2.1 years), were the most significant long-lived artificial radionuclides released from Fukushima-Daiichi Nuclear Power Plants (FDNPP) in 2011. The total amounts released were approximately $20 \mathrm{PBq} .{ }^{1}$ Radiocesium, particularly ${ }^{137} \mathrm{Cs}$, is a long-term radiological concern because of its long half-life and strong

${ }^{a}$ Department of Environment Systems, Graduate School of Frontier Sciences, The University of Tokyo, 7-3-1 Hongo, Bunkyo-ku, Tokyo, 113-8654, Japan. E-mail: ekatengeza@poly.ac.mw

${ }^{b}$ Fukushima Environmental Monitoring Division, Collaborative Laboratories for Advanced Decommissioning Science, Japan Atomic Energy Agency, 45-169 Kaihamasukakeba, Minamisoma, Fukushima, 975-0036, Japan

† Electronic supplementary information (ESI) available. See DOI: 10.1039/d0em00160k adsorption to soil particles. Monitoring of water bodies in areas affected by the FDNPP accident has revealed particle-bound radiocesium accumulating in bottom sediments of lakes and reservoirs; $;^{2,3}$ along river beds and flood plains; $;^{4-6}$ and as the main form of radiocesium transport across media. ${ }^{7}$

In Fukushima prefecture, apart from lakes, rivers, and the ocean; agricultural ponds are of special interest because of their important role in supporting people's livelihood through irrigation agriculture. The prefecture has over 3700 ponds. ${ }^{8}$ Radiocesium levels in sediments of ponds located in areas affected by the FDNPP accident often exceeded $10 \mathrm{kBq} \mathrm{kg}^{-1} .{ }^{9}$ The solidliquid distribution coefficients, $k_{\mathrm{d}}$, of radiocesium in the ponds were higher or comparable to those of lakes and rivers ${ }^{\mathbf{1 0 , 1 1}}$ and an enrichment effect was observed for the ponds' bottom sediments relative to their catchments' soil. ${ }^{10}$ These ponds, like reservoirs, may buffer ${ }^{12-15}$ or spread ${ }^{15,16}$ as radiocesium. 
Most sediment studies of radiocesium in aquatic environments focus on the vertical profiles: their distribution; ${ }^{3}$ their temporal vertical shifts; ${ }^{17}$ and on modelling radiocesium migration processes. Earlier vertical profiles for agricultural ponds in Fukushima had peaks within the surface layer (0-5 $\mathrm{cm})^{5,12}$ with a sharp decrease in concentration beyond that layer. In more recent profiles, ${ }^{\mathbf{1 8}}$ though dependent on sampling location, radiocesium concentration appears to peak below the surface layer with a more gradual falloff beyond the peaks suggesting a downward migration over time. Very few studies document the temporal changes of radiocesium in surface sediments ${ }^{\mathbf{1 9 , 2 0}}$ and so far in Fukushima, no known studies have attempted to evaluate such changes in agricultural ponds. However, evaluating the decreasing rate of radiocesium in bottom sediments is important because sediments account for the largest proportion of the total radiocesium concentration. ${ }^{\mathbf{1 0}}$ Specifically, surface sediments are important because they make radiocesium available for biological circulation $^{21}$ and redistribution via dissolution, resuspension, erosion, and hydraulic flushing.

Temporal changes in radiocesium concentration can be quantified by the effective half-life which accounts for both physical decay and ecological processes ${ }^{20,22,23}$ or the ecological half-life which excludes physical decay. ${ }^{24}$ Most documented
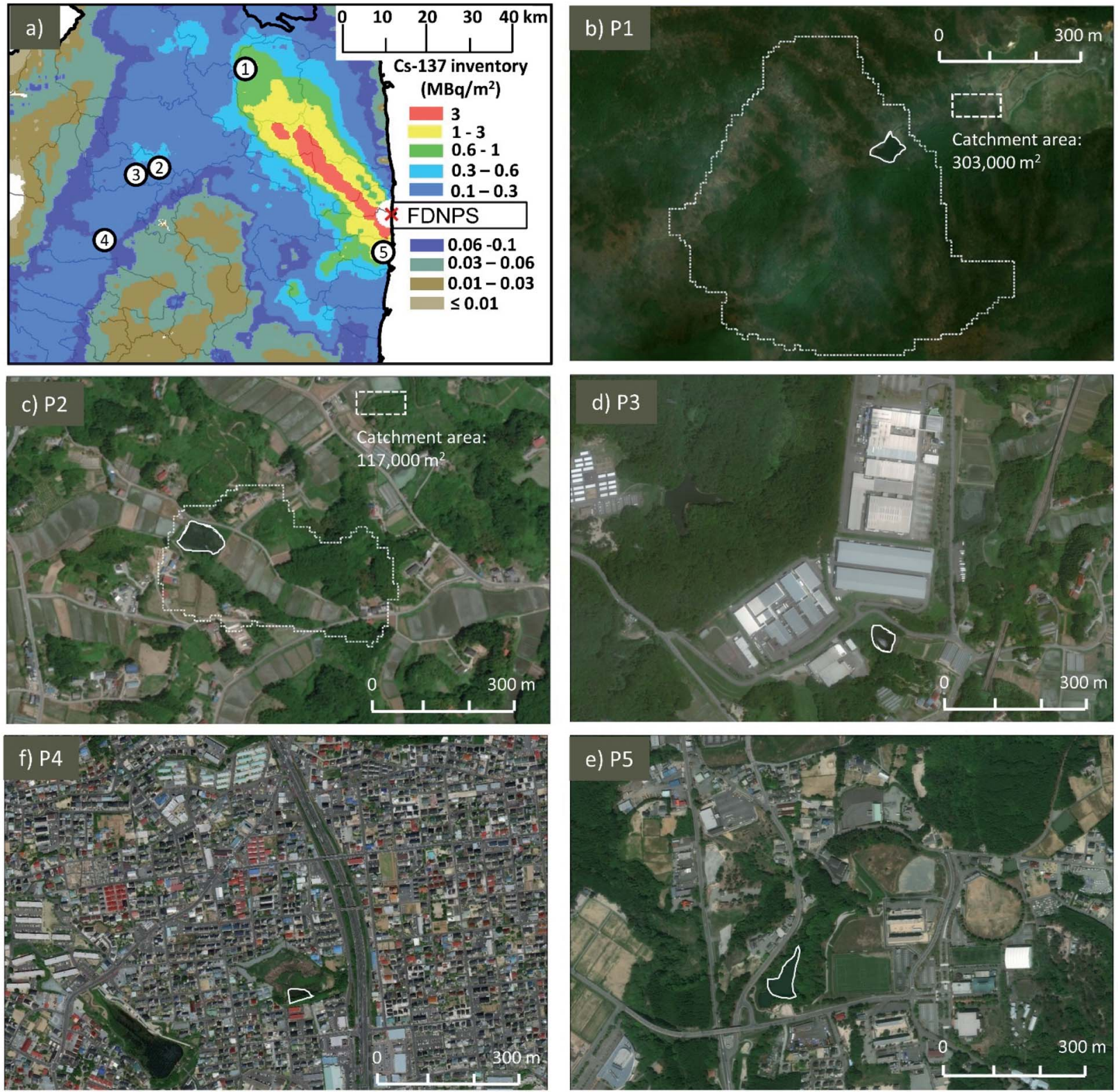

Fig. 1 Radiocesium deposition map (a) showing locations of the sampled ponds. The number corresponds to the code for each pond e.g. point 1 is for pond P1. Satellite images $(b-f)$ show the positions of each pond (unbroken line) and its catchment (broken line). Deposition map is based on the 5th airborne monitoring survey by the Japanese Ministry of Education, Culture, Sports, Science and Technology (MEXT). ${ }^{34}$ Satellite images $($ ) ArC GIS, ESRI, Co, Ltd., USA. 
effective or ecological half-lives of radiocesium, 6 ,19,20,22-24 in either soil or sediments were evaluated from sediment samples thereby providing values for discrete points. Sediment sampling underwater is labour-intensive, long, and becomes expensive for wide area coverage. ${ }^{25}$ Consequently, limited or small sample sizes are characteristic of many sediment studies, which prevents observation of and accountability for spatial heterogeneities across wide areas. ${ }^{25}$

In situ measurement techniques offer an alternative or complement to conventional sampling ${ }^{25-27}$ for wide area spatial distribution under water. Examples of their deployment for radiocesium waterbed surveys include the Fangataufa and Mururoa lagoons ${ }^{\mathbf{2 6 , 2 7}}$ which were nuclear weapon test sites; the Irish sea in the vicinity of the Sellafield Reprocessing Facility ${ }^{26,27}$ and off the coast of FDNPP in Japan..$^{29-31}$ A clear observation is that these studies have primarily focused on marine environments whose underlying hydrodynamics are different from shallow lentic water bodies such as agricultural ponds. With Fukushima's abundance of agricultural ponds, the Japan Atomic Energy Agency (JAEA) developed plastic scintillation fiber (PSF) ${ }^{32,33}$ detector technology for in situ monitoring of their bottom sediments. This technique enables observation of spatial variation in contamination over wide areas. Good agreement was observed between radiocesium concentrations estimated by the PSF and mean radiocesium concentration of sediment cores averaged to a $10 \mathrm{~cm}$ depth $\mathrm{ch}^{32,33}$ thereby validating the results.

The aim of this study was to evaluate the ecological half-life of radiocesium over wide areas of pond surface sediments based on in situ measurements with PSF. Typical ecological halflife estimations focus on surface sediments ${ }^{19,20,22,24}$ based on grab samples or the top layers (up to $10 \mathrm{~cm}$ depth) of sediments. The effective depth of PSF considered in this study is $10 \mathrm{~cm}$ based on the thickness of sediment core samples used to calibrate the PSF concentration since it started being applied. ${ }^{32,33}$ Therefore, the temporal changes reflect what is occurring in this layer of sediments and can provide some useful radioecological information. This is not a radiocesium migration study but rather a study of the overview of the spatialtemporal trends of radiocesium concentration over wide areas of bottom sediments based on in situ measurements with PSF. It is the first attempt to evaluate the ecological half-life over wide areas of bottom sediments, to use in situ measurements in bottom sediments to estimate the ecological half-life, and to study the ecological half-life in bottom sediments of ponds. The ecological half-life is evaluated in the context provided by Prohl et $a .^{24}$ where all processes contributing to a decline in radioactivity, excluding physical decay and human actions such as decontamination (herein, only within the pond), are integrated. It lumps together all potential contributors, within the bulk upper $10 \mathrm{~cm}$ surface-sediment layer.

\section{Experimental}

\section{Study sites}

We selected five ponds located in areas affected by radioactive fallout from the FDNPP accident. Fig. 1 shows the location and satellite images of the ponds and their catchment and Table 1 summarizes their characteristics. Pond P1 is located in a mountainous region with its catchment consisting entirely of the forest. Its average depth is $1.1 \mathrm{~m}$ while its catchment area is $303000 \mathrm{~m}^{2}$. P2 has a mixed catchment consisting of forest (50\%), cultivated land (40\%), and infrastructure (10\%). Its catchment is $117000 \mathrm{~m}^{2}$ and its depth averages $2.1 \mathrm{~m}$. The catchments of P3, P4 and P5 were difficult to isolate as they are mainly determined by the sewage system due to their location in residential areas. Their depths average $0.8 \mathrm{~m}, 1.7 \mathrm{~m}$, and $4.0 \mathrm{~m}$ respectively. $\mathrm{P} 5$ lies within a $10 \mathrm{~km}$ radius of the FDNPP while

Table 1 Description and characteristics of the investigated ponds and their catchment

\begin{tabular}{|c|c|c|c|c|c|}
\hline \multirow[b]{2}{*}{ Characteristic } & \multicolumn{5}{|l|}{ Pond } \\
\hline & $\mathrm{P} 1$ & $\mathrm{P} 2$ & P3 & $\mathrm{P} 4$ & P5 \\
\hline Town/local govt & Iitate & Motomiya & Motomiya & Koriyama & Futaba \\
\hline Area designation $^{a}$ & SDA & ICSA & ICSA & ICSA & SDA \\
\hline Latitude & 37.701801 & 37.513944 & 37.500787 & 37.376372 & 37.348583 \\
\hline Longitude & 140.687407 & 140.478589 & 140.422833 & 140.346835 & 141.013197 \\
\hline Elevation (m) & 498 & 299 & 252 & 250 & 29 \\
\hline Distance from FDNPP (km) & 44 & 52 & 56 & 63 & 8.5 \\
\hline Surface area $\left(\mathrm{m}^{2}\right)^{b}$ & 2320 & 5350 & 858 & 4770 & 5420 \\
\hline Catchment $\left(\mathrm{m}^{2}\right)^{b}$ & 303000 & 117000 & - & - & - \\
\hline Catchment : surface ratio & 131 & 22 & - & - & - \\
\hline \multicolumn{6}{|l|}{ Depth (m) } \\
\hline Maximum & 3.2 & 3.4 & 1.2 & 2.3 & 5.9 \\
\hline Mean & 1.1 & 2.1 & 0.8 & 1.7 & 4.0 \\
\hline Minimum & 0.2 & 0.7 & 0.4 & 1.4 & 0.9 \\
\hline \multicolumn{6}{|l|}{ Catchment land use (\%) } \\
\hline Forest & 100 & 50 & - & - & - \\
\hline Cultivation (paddies, etc.) & - & 40 & - & - & - \\
\hline Infrastructure (road, building, etc.) & - & 10 & - & - & - \\
\hline
\end{tabular}

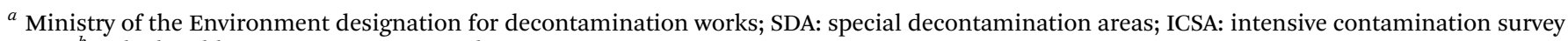
areas. ${ }^{b}$ Calculated by ArCGIS, ESRI, Co, Ltd., USA. 
the others are located between 44 and $63 \mathrm{~km}$ away from the FDNPP. P2 has three main inlets while the other ponds have two.

\section{Measurement campaigns}

Sediment core sampling and in situ measurements with PSF were conducted annually between 2013 and 2019, with approximately one year intervals between sampling campaigns. The specific monitoring dates for each measurement campaign are detailed in Table 2. Ponds P3, P4, and P5 underwent decontamination, by dredging, either before or after the measurement campaigns covered in this paper. P3 was decontaminated in 2013 and 2018 while P4 and P5 were decontaminated in 2018, after the measurement campaigns. For P3, only the data collected between the first and second decontamination were used in the analysis.

\section{In situ measurement system and procedure}

The flexible $20 \mathrm{~m}$ long PSF is submersible in water and uses realtime kinematic global positioning systems to provide the positional count rate, in counts per second (cps), for every $20 \mathrm{~cm}$ length of cable ${ }^{32}$ with a counting time of 100 seconds. The PSF used in this study is an optical fiber, SCSF-3HF (Kuraray Co. Ltd., Japan) consisting of a polystyrene core sequentially clad with polymethylmethacrylate and fluorinated polymers. ${ }^{33}$ The diameter and length of the fiber are $2 \mathrm{~mm}$ and $20 \mathrm{~m}$ respectively. Ten PSFs were gathered into one vinyl tube, and photomultiplier tubes (PMTs) were placed at both ends of the optical fiber. Hereon, PSF refers to PMT-coupled bundled PSFs.

Fig. 2 shows a schematic of the PSF measurement system, adopted from Sanada et al. ${ }^{32}$ The radiation counts are measured by placing the PSF at the bottom of the ponds where radioactive emissions, mostly gamma rays but also beta particles, produce directional scintillation light in the fiber. A time-to-amplitude converter outputs a positional total count spectrum to a computer based on the arrival time difference of the scintillations at each PMT. Positional resolution and the linearity between source and the peak channel are checked by ${ }^{137} \mathrm{Cs}$ point sources as described by Nohtomi et al. ${ }^{35}$ Routine calibration before and after deployment uses radiocesium-spiked concrete calibration pads in a water tank. The conversion factor from the total count rate to the activity concentration was obtained by correlation with ex situ measurements of sediment

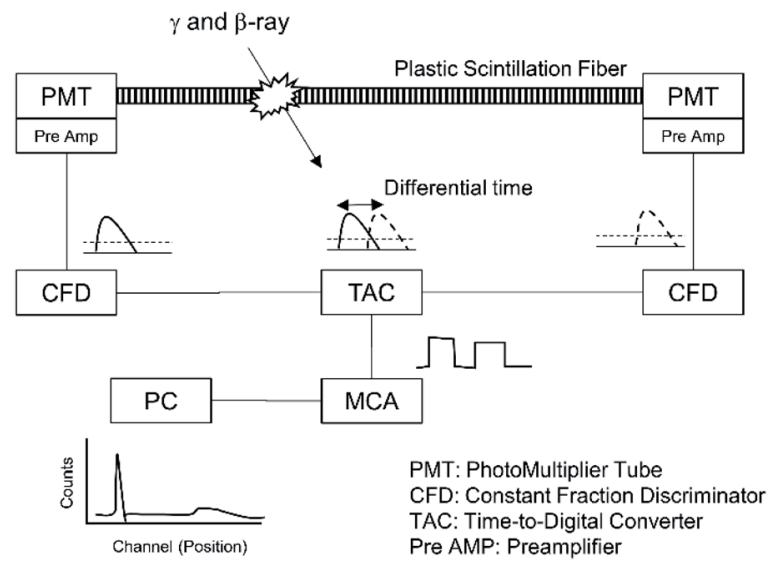

Fig. 2 The PSF measurement system adopted from Sanada et al..$^{32}$

core samples. This process and its results are explained in the next section. The minimum detection limit for radiocesium in ponds was $61 \mathrm{~Bq} \mathrm{~kg}^{-1} \cdot{ }^{32}$ The PSF measurements were taken linearly as shown in Fig. 3 with a spacing of $5 \mathrm{~m}$ between the lines. Approximately the same positions and lines were used during each campaign.

Each pond was divided into grids, the concentration in each mesh was averaged and the mean value was allocated for that mesh. The number of data points used for temporal analysis were determined by the campaign that produced the least data points. This corresponds to the smallest areas on radiation maps which were generated through interpolation by the Kriging method using a geographic information system software, ArC GIS (ESRI Co, Ltd., USA).

\section{Conversion factor}

There are many ways of obtaining conversion factors, CF, from the count rate (cps) to the activity concentration for in situ waterbed detectors. These include ${ }^{28}$ the Monte-Carlo simulation, the use of standard calibration sources with a fitting function, and comparing with the concentration of sediments sampled from the same media where the in situ measurements are taken. This study employed comparison with laboratorymeasured sediment activity concentration. Examples of studies that also employed this kind of calibration are ${ }^{25,36-38}$ and earlier PSF studies. ${ }^{32,33}$

Table 2 Monitoring campaign schedule for PSF. Sediment core samples were also collected during the same period

\begin{tabular}{|c|c|c|c|c|c|c|c|}
\hline \multirow[b]{2}{*}{ Pond } & \multicolumn{7}{|l|}{ Year } \\
\hline & 2013 & 2014 & 2015 & 2016 & 2017 & 2018 & 2019 \\
\hline $\mathrm{P} 1$ & & 7-11 Aug & 28 Aug-14 Sep & 1-6 Sep & 12-Dec & 12-13 Sep & 27-28 Aug \\
\hline $\mathrm{P} 2$ & 31 Jul-2 Aug & & $\begin{array}{l}\text { 10-12 Mar } \\
14-15 \text { Oct }\end{array}$ & & & & \\
\hline P3 & $\begin{array}{l}11-13 \text { Apr } \\
24-26 \text { Sep }\end{array}$ & 24-25 Sep & $\begin{array}{l}4-5 \text { Mar } \\
13-14 \text { Oct }\end{array}$ & & 1-4 Sep & & \\
\hline $\mathrm{P} 4$ & & 11-13 Nov & 3-7 Sep & 2-5 Sep & 4-6 Sep & & \\
\hline P5 & & 28-31 Oct & 20-24 Aug & 26 Aug-16 Sep & 11-Dec & 7-8 Aug & \\
\hline
\end{tabular}



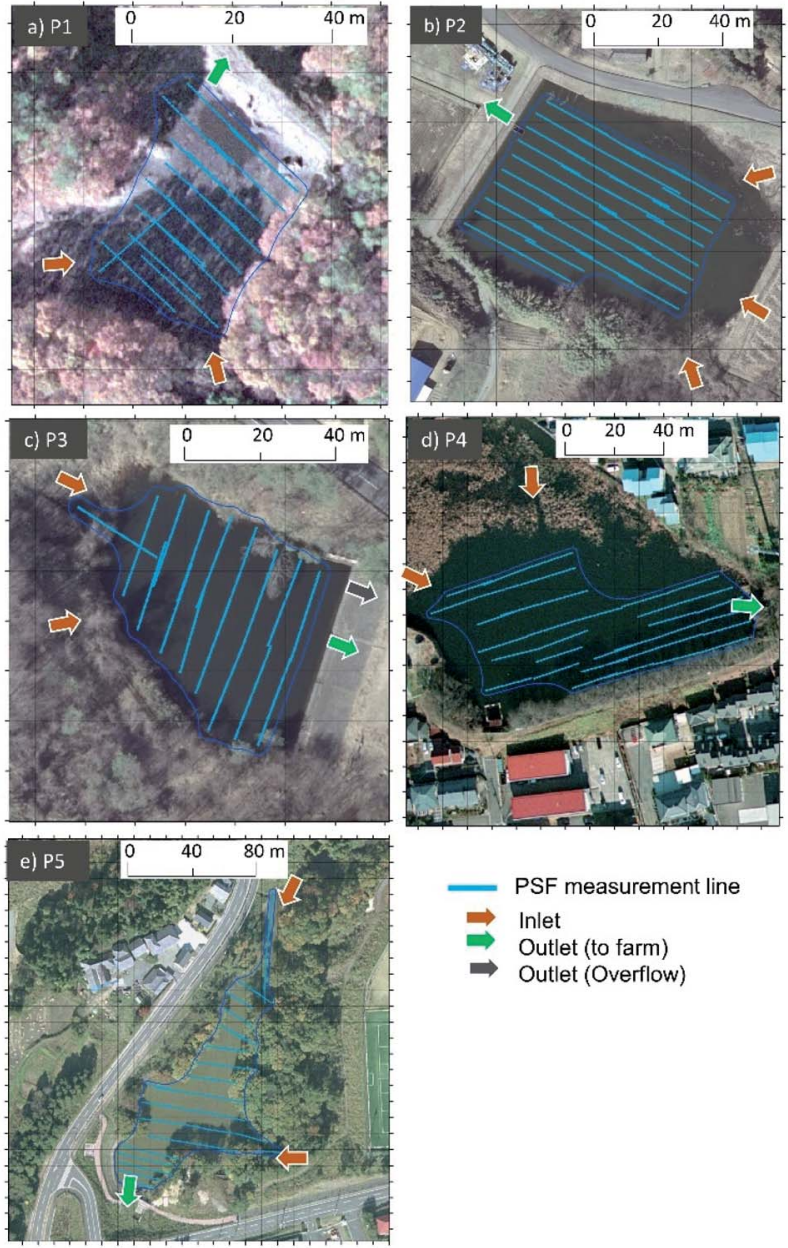

Fig. 3 PSF measuring lines in each studied pond. Also shown are the inlets and outlets of each pond. Satellite images $\odot$ ArC GIS, ESRI, Co, Ltd., USA.

A total of 81 sediment cores were collected from the ponds at points coinciding with PSF measurement lines. Cores were collected using an HR type core sampler (Rigo, Co. Ltd., Japan) after which they were sectioned at $5 \mathrm{~cm}$ intervals and each section was analysed for radiocesium concentration (Bq kg ${ }_{\text {wet }}^{-1}$ ), on a wet basis, using a p-type high-purity germanium detector of $18 \%$ relative efficiency (GEM20-70, Ortec, Seiko EG\&G, USA) coupled to a multichannel analyser (MCA 7, Ortec, Seiko EG\&G, USA). The average water content of these sediment samples $(0-10 \mathrm{~cm}$ ) was $60.2 \%$ (Min: $52.0 \%$; Max: $81.0 \%)$. Standard gamma sources were used to calibrate the spectrometer: ${ }^{241} \mathrm{Am},{ }^{109} \mathrm{Cd}$ and ${ }^{152} \mathrm{Eu}$ (EG-CUSTOM, Isotope Products Laboratories, USA); ${ }^{210} \mathrm{~Pb}$ and ${ }^{137} \mathrm{Cs}$ (EG-CUSTOM, Isotope Products Laboratories, USA). PSF are a total count system, hence the measured ${ }^{137} \mathrm{Cs}$ and ${ }^{134} \mathrm{Cs}$ concentrations for the top two layers (totalling $10 \mathrm{~cm}$ depth) were summed and averaged, then compared with the count rate obtained by the PSF. Fig. 4a shows the comparison between the radiocesium concentration of sediment core samples and the counts obtained by the PSF system. To account for outliers observed in the scatter plot (Fig. 4a), a CF was calculated for each PSF-core a)

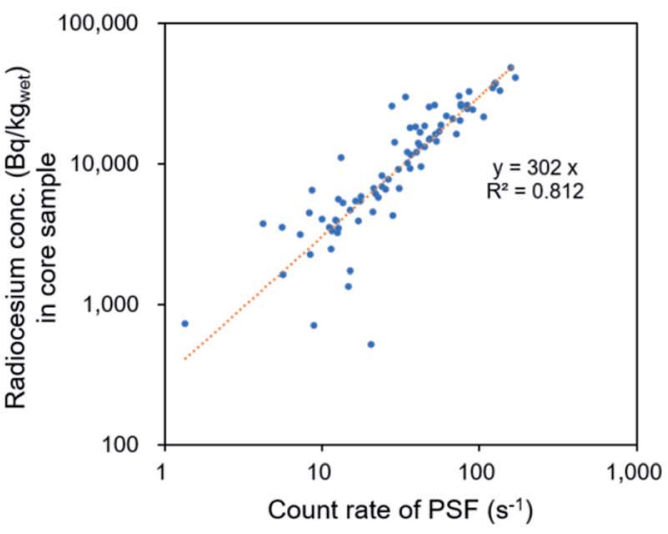

b)

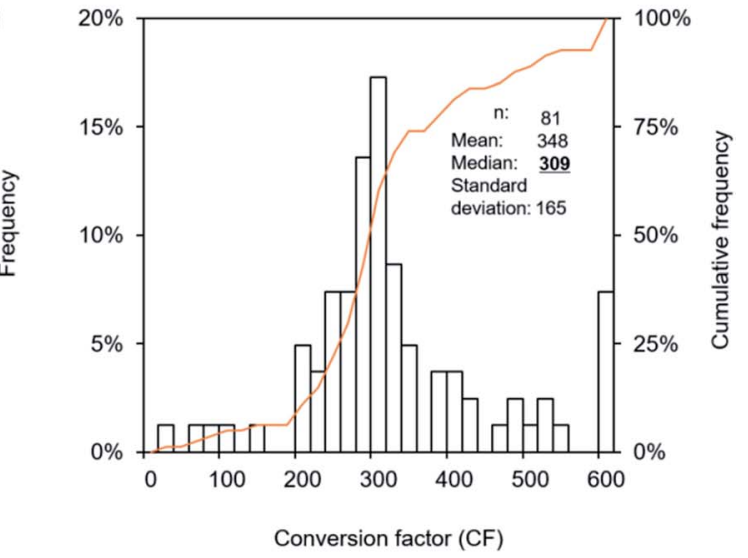

Fig. 4 Relationship between radiocesium concentration by sediment core samples and the counts obtained by the PSF measurement system (a) and distribution of conversion factors (b).

data set and the median (309 $\left.\mathrm{cps}\left(\mathrm{Bq} \mathrm{kg}_{\mathrm{wet}}{ }^{-1}\right)^{-1}\right)$ of their frequency distribution (Fig. 4b) was considered appropriate and applied in this study. The standard deviation of the CF, $165 \mathrm{cps}$ $\left(\mathrm{Bq} \mathrm{kg} \mathrm{wet}^{-1}\right)^{-1}$, accounts for $53 \%$ of the median value. Uncertainty may arise from: (a) imprecise PSF-coincident core sampling points due to possible instability of boats during sampling; (b) variation in water content and radiocesium concentration depth profile of the core; (c) the detection mechanism of PSF because it does not distinguish the type and energy of the detected radiation, which is predominantly gamma rays but can include beta particles; and (d) inefficient detection of gamma rays at the deeper end of the depth captured by PSF, which is up to $10 \mathrm{~cm}$. Despite these potential sources of uncertainty, there was a strong agreement $\left(R^{2}=0.81\right.$, Fig. 4a).

To minimize point (a), care was taken to collect core samples within $20 \mathrm{~cm}$ to $2 \mathrm{~m}$ of PSF lines. Assuming unchanging water content of the sediments, points (b) to (d) would have a negligible effect on the temporal trend within the $10 \mathrm{~cm}$ surface sediment layer because measurement lines were maintained in each campaign so that differences would serve to reflect changes occurring within the surface layer captured by PSF. 


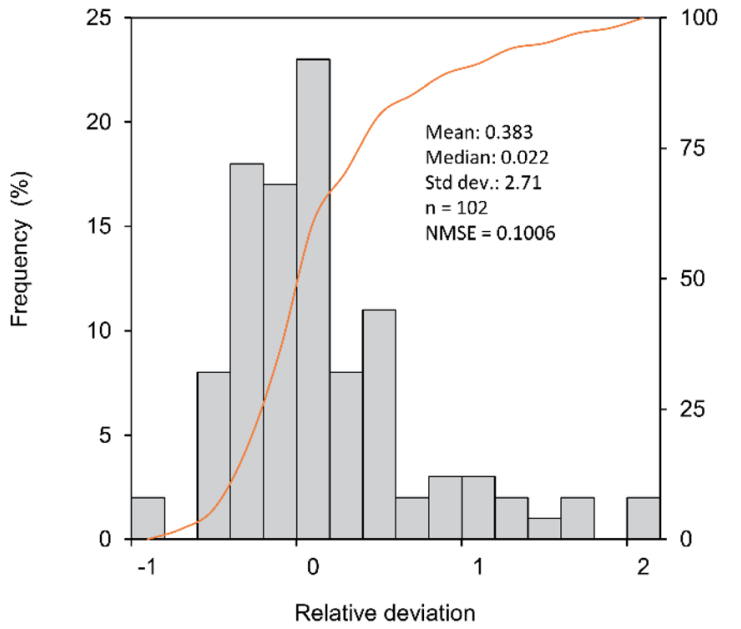

Fig. 5 Distribution of the relative deviation of PSF-determined ${ }^{137} \mathrm{Cs}$ concentration to that of core samples.

\section{Estimation of the ecological half-life}

In this study, temporal analysis was based on the premise of exponential decay using a first-order kinetic equation ${ }^{20}$ that assumes that the rate of decrease of radiocesium concentration does not change within the time scale we dealt with. The measured PSF concentration was first corrected for physical decay of ${ }^{134} \mathrm{Cs}$ (half-life $=2.1$ years) and ${ }^{137} \mathrm{Cs}$ based on the number of half-lives, $N_{\mathrm{HL}}$, exhausted at measurement time from 15 March 2011. The concentration of ${ }^{137} \mathrm{Cs}\left(A_{137}\right)$ was evaluated from the ratio of its ${ }_{137} N_{\mathrm{HL}}$ to that combined with ${ }^{134} \mathrm{Cs}$, total $N_{\mathrm{HL}}$. The concentration of ${ }^{137} \mathrm{Cs}$ was converted from the count rate of the PSF with eqn (1):

$$
A_{137}=C_{\mathrm{r}} \mathrm{CF} \frac{\exp \left(-\lambda_{137} t\right)}{\exp \left(-\lambda_{137} t\right)+\exp \left(-\lambda_{134} t\right)}
$$

where $C_{\mathrm{r}}$ is count rate of PSF, CF is the conversion factor evaluated in the preceding section and $t$ is the time elapsed (year) from the main radioactive fallout date (15 March 2011). The nuclide ratio of ${ }^{137} \mathrm{Cs}$ and ${ }^{134} \mathrm{Cs}$ was one at the time of the accident. To ascertain this approach, the relative deviation of $A_{137}$ to that of core samples was calculated as described in ref. 38 and their distribution is shown in Fig. 5. The mean and median are very close to zero, indicating a good fit. On average, $A_{137}$ deviated from the radiocesium concentration of core samples by $38 \%$ with a median of $2.2 \%$. The normalized mean square error (NMSE) was 0.1006 . The ${ }^{137} \mathrm{Cs}$ concentrations were used with eqn (2) to determine their ecological half-life, $T_{\text {eco}}$.

$$
A_{t}=A_{0} \exp \left(-\frac{\ln 2}{T_{\text {eco }}} t\right)
$$

where $A_{0}$ and $A_{t}$ are the ${ }^{137} \mathrm{Cs}$ concentration initially and after time, $t$, from the main radioactive fallout date. The parameters $A_{0}$ and $T_{\text {eco }}$ were evaluated by the method of least-squares where the absolute value of the slope is $\ln 2 / T_{\text {eco. }}$. With this treatment, the half-life, $T_{\text {eco }}$, only depicts the ecological component which in this study, partly includes an element catchment decontamination.
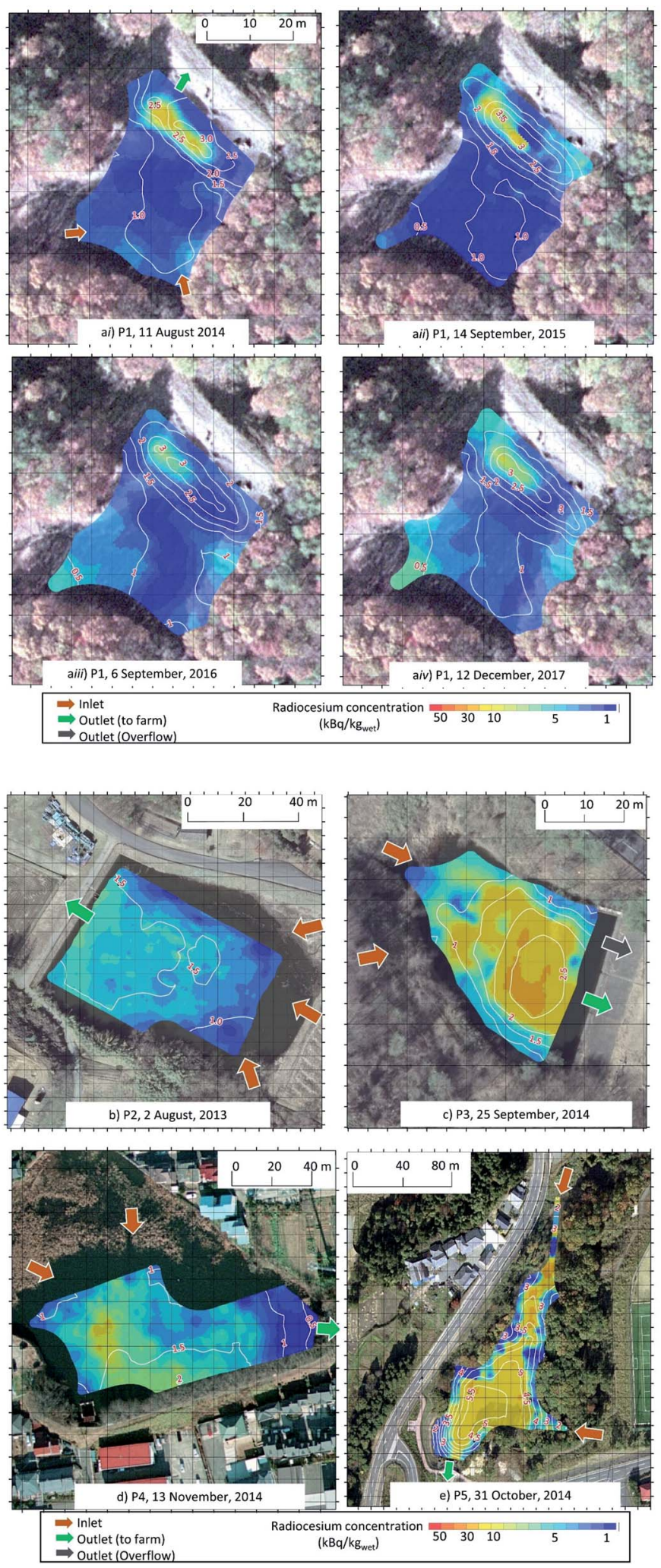

Fig. 6 (a) Radiation maps generated from PSF data and illustrating temporal changes for ponds P1. The maps depict concentrations at the measurement time. Satellite images (c) ArC GIS, ESRI, Co, Ltd., USA. (b-e) Radiation maps generated from PSF data and illustrating temporal changes for ponds P2 to P5 (b to e). The maps depict concentrations at the measurement time. Satellite images $\odot$ ArC GIS, ESRI, Co, Ltd., USA. 

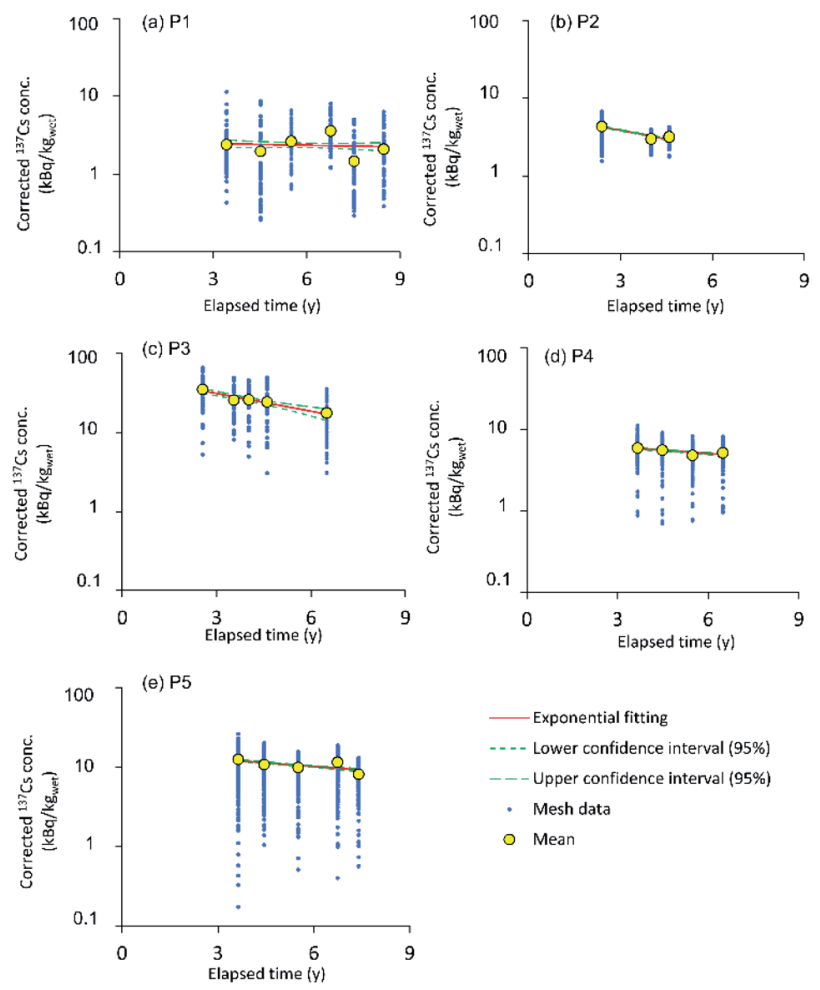

Fig. 7 Temporal changes in ${ }^{137} \mathrm{Cs}$ concentration with an exponential fit calculated from the evaluated $T_{\text {eco }}$ and $a_{0} \cdot{ }^{137} \mathrm{Cs}$ concentration was corrected for physical decay from 15 March 2011. Also shown are the upper $(95 \%)$ and lower (95\%) confidence intervals.

\section{Results and discussion}

\section{Spatial heterogeneity of radiocesium concentration}

PSF measurements over whole ponds show spatial heterogeneity in radiocesium concentration throughout the monitoring period reported in this study. These spatial variations are illustrated through the radiation maps (Fig. 6 and S1 $\dagger$ ), where hotter colours indicate higher concentrations and colder colours show lower concentrations, the spread of the mesh data points (Fig. 7) and large standard deviations, ${ }^{30}$ in the radiocesium concentrations. The 2015 mean (and standard deviation) for P1 to P5 were $2.3(2.9) \times 10^{3} \mathrm{~Bq} \mathrm{~kg}_{\text {wet }}{ }^{-1}, 3.4 \times 10^{3}(6.8$ $\left.\times 10^{2}\right) \mathrm{Bq} \mathrm{kg}_{\text {wet }}{ }^{-1}, 1.4 \times 10^{4}\left(6.9 \times 10^{3}\right) \mathrm{Bq} \mathrm{kg}_{\text {wet }}{ }^{-1}, 6.4 \times 10^{3}$ $\left(1.9 \times 10^{3}\right) \mathrm{Bq} \mathrm{kg}_{\mathrm{wet}}{ }^{-1}$, and $1.3 \times 10^{4}\left(4.9 \times 10^{3}\right) \mathrm{Bq} \mathrm{kg}_{\text {wet }}{ }^{-1}$ respectively. These PSF-generated radiation maps and quantitative data provide good information on the horizontal distribution on the ponds' waterbed which can aid in the selection of sites for studies requiring core-sampling, thereby addressing uncertainties associated with the patterns of sediment deposition, ${ }^{21}$ common to radiocesium accumulation studies. For core samples, the average depth at which $90 \%$ of radiocesium occurred was $11.5 \pm 4.4 \mathrm{~cm}$. The histogram for this distribution is shown in the ESI (Fig. S2†).

There is a tendency for higher concentration of radiocesium in deeper areas (Fig. 6a-e) in the ponds, similar to the observation for the Chernobyl-derived radiocesium inventory in Lakes Päijäne ${ }^{39}$ and Høysjøen ${ }^{40}$ in Finland and Norway respectively. These observations of enhanced sediment (and, consequently, radiocesium) accumulation in deeper parts of the waterbed were defined as sediment focusing. This effect was also observed with FDNPP-derived radiocesium on the waterbed of the Ogi reservoir ${ }^{41}$ and the Ukedo river estuary. ${ }^{42}$ Thornton et al. ${ }^{30}$ observed patterns of elevated radiocesium concentration at bases of protrusions in the seabed near FDNPP using a towed gamma spectrometer. Our results reveal the occurrence of similar phenomena in ponds. For P1 (Fig. 6a(i-vi)) and P2 (Fig. 6b) these deeper and higher concentration areas are at the outlets while the inlets have lower concentrations. Ohnuma and Ishii ${ }^{18}$ found coarser lowconcentration sediments prevailing at inlets and finer radiocesium-rich sediments dominating at the outlets of ponds. Funaki et al. ${ }^{3}$ observed a similar trend in sediment size distribution between the inlet and outlet of the Ogaki dam. The finer sediments dominating at outlets was attributed to lower settling velocities which transport them further than the heavier and courser sediments. ${ }^{3}$ This particle size dependence may reflect our results.

\section{Temporal changes in radiocesium concentration}

Fig. 7 shows the PSF mesh data, the overall mean values and the exponential fitting line for the mean values. The radiocesium concentration in all the ponds declines, albeit at different rates, with P1 having a long $T_{\text {eco }}$ P2 and P3 having short $T_{\text {eco; }}$ and P4 and P5 having intermediate $T_{\text {eco }}$ (Table 3 ). Since this study accounted for the physical decay in the analysis, this means the effective half-life in all the ponds is shorter than the physical half-life. The likely main contributors to the declining trend include (a) hydraulic flushing out of sediments and (b) downward migration of radiocesium through sedimentation and diffusion-advection. Hydraulic flushing may strongly affect shallow ponds (for example P1, P3 and P4) because they can be easily agitated by strong winds, ${ }^{17,43}$ heavy rains and typhoons; ${ }^{15}$ and ponds of large catchment-to-surface-area ratios which yield low radiocesium trap efficiency ${ }^{21}$ so that radiocesium-rich fine sediments are flushed out. Yoshimura et al. ${ }^{44}$ observed such hydraulic flushing in some Fukushima ponds of low trap efficiency. Sedimentation is more likely to produce a larger ecological half-life, as inferred by Juranova et $a .^{20}$ and Baltas

Table 3 Summary of the initial ${ }^{137} \mathrm{Cs}$ concentration $\left(a_{0}\right)$ and ecological half-lives $\left(T_{\text {eco }}\right)$ for the five ponds estimated from measurements with PSF

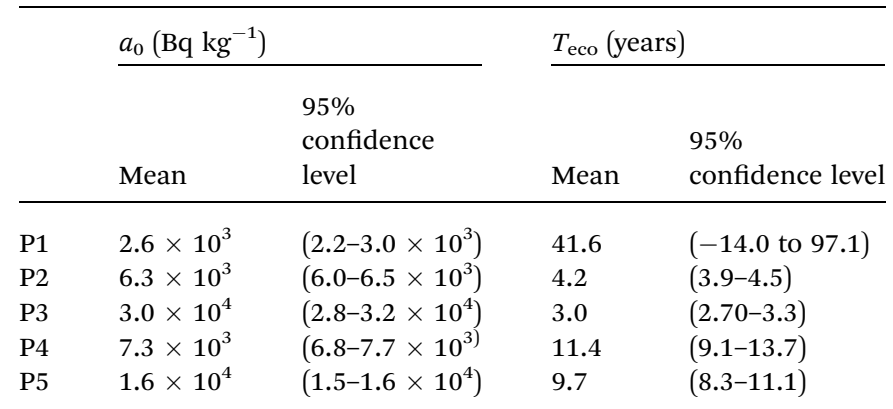


et $a l .{ }^{19}$ because it adds to the radiocesium concentration. This may explain P1's long $T_{\text {eco }}, 42 \pm 55$ years, where the radiation maps (Fig. 6a) show increased radiocesium concentration for 2016 (Fig. 6a(iii)) and 2017 (Fig. 6a(iv)) compared to 2015 (Fig. 6a(ii)) in an area near the top left inlet.

The observed apparent sedimentation in P1 seems contradictory to the expectation of low soil erosion from forest catchments. $^{7,45}$

However, findings by Walling and Quingping, ${ }^{46}$ Yoshimura et $a .^{45}$ and Taniguchi et al. ${ }^{7}$ show that sediments eroded from forested or, generally, uncultivated catchments tend to be radiocesium-rich. This is the most probable explanation for the observation in P1. Sometimes sedimentation may result in an overall increase in concentration so that the $T_{\text {eco }}$ takes on a positive value. This is captured within the large standard deviation of P1's $T_{\text {eco. }}$. On the other hand, radiocesium concentration is relatively smaller in sediments eroded from cultivated $^{\mathbf{4 6}}$ and/or decontaminated ${ }^{47}$ catchments even though erosion rates are higher therein. Therefore, comparable quantities of sediments entering P2-P5 may have relatively lower radiocesium concentration than in $\mathrm{P} 1$. This may also explain the observed $T_{\text {eco. }}$. Decontamination efforts in Fukushima's Special Decontamination Areas (SDA) and Intensive Contamination Survey Areas (ICSA) prioritise living spaces including infrastructure, farmlands and only portions of forests near areas frequented by people. ${ }^{48}$ Whole area decontamination was completed on 19 March, 2018 in ICSA and on 31 March 2017 and 4 March 2020 in Iitate and Futaba respectively. ${ }^{49}$

To observe the local variability in the $T_{\text {eco }}$ across P1, a grid by grid analysis was conducted. Each $5 \mathrm{~m}$ by $5 \mathrm{~m}$ grid had six data points, one for each campaign. The grids had been categorized according to the evaluated $T_{\text {eco }}$ with category $\mathrm{A}$ of a $T_{\text {eco }}$ less than 5 years, category B $T_{\text {eco }}$ between 5 and 10 years, category $\mathrm{C} T_{\text {eco }}$ between 10 and 100 years, and category $\mathrm{D} T_{\text {eco }}$ over 100 years. No negative $T_{\text {eco }}$ was observed. Fig. 8 shows the distribution of the $T_{\text {eco }}$ in P1, color-coded for each category. The grids were $19 \%$ category A, $16 \%$ category B, $15 \%$ category C and 50\% category D. Most category D grids coincide with areas displaying possible sedimentation such as the top-left inlet, extending to a portion of the central area, and the deepest parts of the pond at the outlet, including the hotspot region (Fig. 6a). Juranova et al. ${ }^{20}$ interpreting a long ${ }^{137} \mathrm{Cs} T_{\text {eco }}(370 \pm 450$ years $)$ of sediment sampled at the Otava Pisek tributary of Vltava river in The Czech Republic, suggested an effective blocking of ${ }^{137} \mathrm{Cs}$ removal by ecological processes as a result of sediment aging in combination with ${ }^{137} \mathrm{Cs}$ influx from the catchment. Fukushima et al. ${ }^{17}$ observed a monotonic increase in the FDNPP-derived radiocesium inventory at the centres of four Japanese lakes, which was attributed to catchment input or lateral sediment transport within the lakes. Similarly, the inter-grid $T_{\text {eco }}$ variations may be related to levels of sedimentation. They may also be associated with granulometry, mineralogy, and geophysical chemistry, which are outside the scope of the present study. Even though this technique does not provide the exact ecological processes, an overview of what is occurring has been obtained, which can optimize sediment sampling for specific migration studies.

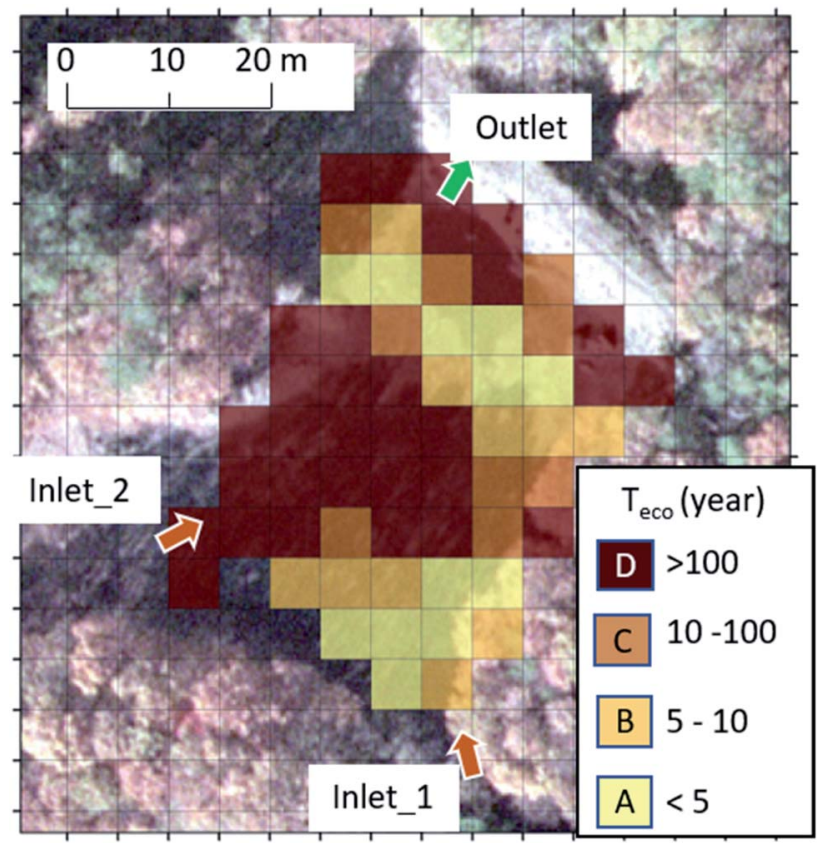

Fig. 8 Grid by grid distribution of the PSF-based ecological half-lives in P1. The color codes correspond to the different categories (A, B, C, and $D)$ defined by the range of $T_{\text {eco }}$ as shown in the legend. Satellite image (c) ArC GIS, ESRI, Co, Ltd., USA.

The $T_{\text {eco }}$ for P2 to P5 range from 3.0 to 11.4 years (Table 3). P3 was decontaminated prior to the first measurement campaign and has the shortest $T_{\text {eco }}$ but it is presently unclear if this is responsible for the observed $T_{\text {eco }}$. No correlation was observed between the $T_{\text {eco }}$ and the pond characteristics among P3-P5.

While a short $T_{\text {eco }}$, such as for P2 to P5, may be considered a form of spontaneous decontamination, recontamination concerns may arise for areas onto which the ponds irrigate or overflow if hydraulic flushing is the dominant process. On the other hand, the longer $T_{\text {eco, }}$, for example in P1, generates concerns regarding long-term secondary supply of radiocesium from the catchment. The ${ }^{137} \mathrm{Cs}$ average concentration for 52 Finnish lakes in 1992 was $27.4 \%$ of that in $1987,{ }^{50}$ equivalent to a $T_{\text {eco }}$ of 2.93 years.

It was not possible to make a statistical comparison among the ponds by catchment type and dominant land use due to limitations in the available data. However, the results can be used as case studies on the applicability of PSF to overview the relative distribution of radioactivity and quantify the temporal trends over wide areas from averaged data. Additionally, ponds are a type of lentic system characterized by mostly static waters unless agitated by winds or rains. There are no documented studies on the radiocesium $T_{\text {eco }}$ for bottom sediments of ponds associated with fallout from nuclear tests and the accidents in Chernobyl and Fukushima. Also, lentic system studies have focused on larger lakes with radiocesium migration as the dominant research theme. Thus, this study provides novel case studies for (a) the $T_{\text {eco }}$ of radiocesium in sediments of ponds in Fukushima, (b) evaluating the $T_{\text {eco }}$ of radiocesium over wide areas of bottom sediments and (c) evaluating the $T_{\text {eco }}$ of radiocesium in the bottom sediments using in situ measurement 
with PSF. The $T_{\text {eco }}$ is an apparent value including both removal or downward migration of sediment and additional sedimentation. However, this apparent value can represent the real temporal change of radiocesium concentration in surface sediment making it a practical radioecological parameter.

\section{Conclusions}

In this study, the spatial-temporal changes in radiocesium concentration of bottom sediments over wide pond areas were quantified using data obtained by in situ radioactivity monitoring with plastic scintillation fibers (PSF). The decreasing trend of radiocesium was quantified by the ecological half-life which ranged from $3.0 \pm 0.3$ to $11.4 \pm 2.3$ years across three ponds draining residential areas, and was $4.2 \pm 0.3$ years in a mixed-catchment pond and $41.6 \pm 55.5$ years in a forestcatchment pond. PSF-generated spatial distribution patterns showed apparent sediment focusing in the ponds and, over time, catchment-derived radiocesium input for the forest catchment pond. Detailed grid-by-grid analysis for the forestcatchment pond demonstrated longer ecological half-lives across areas of potential sedimentation and sediment focusing. Thus, the ecological half-life is likely influenced by sedimentation and sediment focusing. Though specific ecological processes are not provided by the PSF technique, a useful overview is provided which can help focus and optimize the design of detailed study. The study also confirmed that forest catchments are potential secondary sources of contamination for their drainage basins. This ecological half-life is an apparent value that can represent the real rate of temporal change of radiocesium concentration in surface sediments.

\section{Conflicts of interest}

There are no conflicts to declare.

\section{Acknowledgements}

This work was supported by the Environmental Radioactivity Research Network Center (No. Y-19-25). The authors gratefully acknowledge members of Midori net Fukushima, OYO Corporation, the Japan Radiation Engineering Corporation, NESI Corporation, and the Japan Atomic Energy Agency for assistance with collecting and measuring sediment samples.

\section{Notes and references}

1 H. Terada, H. Nagai, K. Tsuduki, A. Furuno, M. Kadowaki and T. Kakefuda, Refinement of source teram and atmospheric dispersion simulations of radionuclides during the Fukushima Daiichi Nuclear Power Station accident, J. Environ. Radioact., 2020, 213, 106104.

2 L. Cao, N. Ishii, J. Zheng, M. Kagami, S. Pan, K. Tagami and S. Uchida, Vertical distributions of $\mathrm{Pu}$ and radiocesium isotopes in sediments from Lake Inba after the Fukushima Daiichi Nuclear Power Plant accident: Source identification and accumulation, Appl. Geochem., 2017, 78, 287.
3 H. Funaki, K. Yoshimura, K. Sakuma, S. Iri and Y. Oda, Evaluation of particulate ${ }^{137} \mathrm{Cs}$ discharge from a mountainous forested catchment using reservoir sediments and sinking particles, J. Environ. Radioact., 2018, 189, 48.

4 A. Konoplev, V. Golosov, G. Laptev, K. Nanba, Y. Onda, T. Takase, Y. Wakiyama and K. Yoshimura, Behavior of accidently released radiocesium in soil-water environment: looking at Fukushima from a Chernobyl perspective, $J$. Environ. Radioact., 2016, 151, 568.

5 T. Nakanishi, S. Sato and T. Matsumoto, Temporal changes in radiocesium deposition on the Fukushima floodplain, Radiat. Prot. Dosim., 2019, 184, 311.

6 K. Shizuma, W. I. Nursal and Y. Sakurai, Long-term monitoring of radiocesium concentration in sediments and river water along five rivers in Minami-Soma City during 2012-2016 following the Fukushima Dai-ichi Nuclear Power Plant Accident, Appl. Sci., 2018, 8, 1319.

7 K. Taniguchi, Y. Onda, H. G. Smith, W. Blake, K. Yoshimura, Y. Yamashiki, T. Kuramoto and K. Saito, Transport and Redistribution of Radiocesium in Fukushima Fallout through Rivers, Environ. Sci. Technol., 2019, 53, 12339.

8 Ministry of Agriculture, Forestry and Fisheries, Japan, http:// www.maff.go.jp/j/nousin/bousai/bousai_saigai/b_tameike/ attach/pdf/index-65.pdf, (accessed on 23 July, 2019).

9 Fukushima prefecture, https://www.pref.fukushima.lg.jp/ download/1/1114kennnaiteishitunoudobunnpu.pdf, (accessed on 10 October, 2019).

10 Y. Wakiyama, A. V. Konoplev, T. Wada, T. Takase, I. Byrnes, M. Carradine and K. Nanba, Behavior of ${ }^{137} \mathrm{Cs}$ in ponds in the vicinity of the Fukushima Dai-ichi nuclear power plant, J. Environ. Radioact., 2017, 178-179, 367.

11 A. V. Konoplev, Y. Wakiyama, T. Wada, V. N. Golosov, K. Namba and T. Takase, Radiocesium in ponds in the near zone of Fukushima Dai-ichi NPP, Water Resour., 2018, 45, 589.

12 Y. Aoi, K. Fukushi, T. Itono, N. Kitadai, K. Kashiwaya, H. Yamada, T. Hatta and Y. Manpuku, Distribution and mineralogy of radioactive $\mathrm{Cs}$ in reservoir sediment contaminated by the Fukushima nuclear accident, $J$. Mineral. Petrol. Sci., 2014, 109, 23.

13 H. Kurikami, A. Kitamura, S. T. Yokuda and Y. Onishi, Sediment and ${ }^{137} \mathrm{Cs}$ behaviors in the Ogaki Dam Reservoir during a heavy rainfall event, J. Environ. Radioact., 2014, 137, 10.

14 S. Yamada, A. Kitamura, H. Kurikami, M. Yamaguchi, A. Malins and M. Machida, Sediment and ${ }^{137}$ Cs transport and accumulation in the Ogaki Dam of eastern Fukushima, Environ. Res. Lett., 2015, 10, 014013.

15 O. Evrard, C. Chartin, Y. Onda, H. Lepage, O. Cerdan, I. Lefevre and S. Ayrault, Renewed soil erosion and remobilization of radioactive sediment in Fukushima coastal rivers after the 2013 typhoons, Sci. Rep., 2014, 4, 4574 .

16 G. Mouri, V. Golosov, M. Shiiba and T. Hori, Assessment of the cesium-137 flux adsorbed to suspended sediment in 
a reservoir in the contaminated Fukushima region in Japan, Environ. Pollut., 2014, 187, 31.

17 T. Fukushima, E. Komatsu, H. Arai, K. Kamiya and Y. Onda, Shifts of radiocesium vertical profiles in sediments and their modelling in Japanese lakes, Sci. Total Environ., 2018, 615, 741.

$18 \mathrm{~T}$. Ohnuma and K. Ishii, Study of soil particles contaminated with radioactive cesium in pond sediment, Cogent Eng., 2019, 6, 1662573.

19 H. Baltas, M. Siri, G. Dalgic and U. Cevik, An overview of the ecological half-life of the ${ }^{137} \mathrm{Cs}$ radioisotope and a determination of radioactivity levels in sediment samples after Chernobyl in the Eastern Black Sea, Turkey, J. Mar. Syst., 2018, 177, 21.

20 E. Juranova, E. Hanslik and D. Maresova, Temporal development of radiocesium and radiostrontium concentrations in the hydrosphere-methods of evaluation, Water, Air, Soil Pollut., 2015, 226, 335.

21 S. Pulley, I. D. L. Foster, A. L. Collins, Y. Zgang and J. Evans, An analysis of potential controls on long-term ${ }^{137} \mathrm{Cs}$ accumulation in the sediments of UK lakes, J. Paleolimnol., 2018, 60, 1.

22 M. H. Paller, G. T. Jannick and P. D. Fledderman, Effective half-life of cesium-137 in various environmental media at the Savannah River Site, J. Environ. Radioact., 2008, 99, 1302.

23 M. H. Paller, G. T. Jannick and R. A. Baker, Changes in ${ }^{137} \mathrm{Cs}$ concentrations in soil and vegetation on the floodplain of the Savannah River over a 30-year period, J. Environ. Radioact., 2014, 131, 81.

24 G. Prohl, S. Ehlken, I. Fiedler, G. Kirchner, E. Klemt and G. Zibold, Ecological half-lives of ${ }^{90} \mathrm{Sr}$ and ${ }^{137} \mathrm{Cs}$ in terrestrial and aquatic ecosystems, J. Environ. Radioact., 2006, 91, 41.

25 J. M. Miller, B. W. Thomas, P. D. Roberts and S. C. Creamer, Measurement of Marine Radionuclide Distribution Using a Towed Sea-bed Spectrometer, Mar. Pollut. Bull., 1982, 13, 315.

26 I. Osvath, P. Povinec, L. Huynh-Ngoc and J. F. Comanducci, Underwater gamma surveys of Mururoa and Fangataufa lagoons, Sci. Total Environ., 1999, 237-238, 277.

27 I. Osvath and P. P. Povinec, Seabed $\gamma$-ray spectrometry: applications at IAEA-MEL, J. Environ. Radioact., 2001, 53, 335.

28 D. G. Jones, Development and applications of marine gamma-ray measurements: a review, J. Environ. Radioact., 2001, 53, 313.

29 B. Thornton, S. Ohnishi, T. Ura, N. Odano and T. Fujita, Continuous measurements of radionuclide distribution off Fukushima using a towed sea-bed gamma-ray spectrometer, Deep-Sea Res., 2013, 179, 10.

30 B. Thornton, S. Ohnishi, T. Ura, N. Odano, S. Sasaki, T. Fujita, T. Watanabe, T. Ono and D. Ambe, Distribution of local ${ }^{137} \mathrm{Cs}$ anomalies on the seafloor near Fukushima Dai-ichi Nuclear Power Plant, Mar. Pollut. Bull., 2013, 74, 344.

$31 \mathrm{H}$. Kofuji, In situ measurement of ${ }^{134} \mathrm{Cs}$ and ${ }^{137} \mathrm{Cs}$ in seabed using underwater $\gamma$-spectrometry systems: application in surveys following the Fukushima Dai-ichi Nuclear Power Plant accident, J. Radioanal. Nucl. Chem., 2015, 303, 1575.

32 Y. Sanada, Y. Urabe, T. Orita, Y. Takamura and T. Torii, Insitu measurement of radiation distribution in bottom sediments of irrigation ponds using plastic scintillation fiber, The Proceedings of the International Conference on Nuclear Engineering, JSME, ICONE23-2120, 2015.

33 Y. Sanada, Environmental measurement using plastic scintillation fiber after the accident at the Fukushima Daiichi Nuclear Power Plant, Jpn. J. Opt., 2016, 45, 300.

$34 \mathrm{H}$. Kato and Y. Onda, Initial Deposition within Fukushima Prefecture Area Following the Fukushima Daiichi Nuclear Power Plant Accident, CRiED, University of Tsukuba, 2019.

35 A. Nohtomi, N. Sugiura, T. Itoh and T. Torii, Online evaluation of spatial dose-distribution by using a $15 \mathrm{~m}$ long plastic scintillation-fiber detector, 2008 IEEE Nuclear Science Symposium Conference Record, Dresden, 2008, pp. 965-968.

36 A. Bastin, Natural radioactive tracers and their use in Belgium: Lithological maps of the bottom of the North Sea off the Belgian coast and the Scheldt estuary constructed on the basis of natural radioactivity measurements, in Tracer Techniques in Sediment Transport, International Atomic Energy Agency Technical Report Series No. 145, Vienna, 1973, pp. 179-200.

37 D. G. Jones, P. D. Roberts and J. M. Miller, The distribution of gamma-emitting radionuclides in surface subtidal sediments near the Sellafield Plant, Estuar. Coast Shelf Sci., 1988, 27, 143.

38 K. Ochi, Y. Urabe and T. Yamada, Development of an analytical method for estimating three-dimensional distribution of sediment-associated radiocesium at reservoir bottom, Anal. Chem., 2018, 90, 10795.

39 P. H. Kansanen, T. T. Jaakkola, S. Kulmala and R. Suurarinen, Sedimentation and distribution of gammaemitting radionuclides in bottom sediments of southern Lake Päijänne, Finland, after the Chernobyl accident, Hydrobiologia, 1991, 222, 121.

40 I. A. Blakar, D. Hongve and O. Njåstad, Chernobyl cesium in the sediments of Lake Høysjøen, Central Norway, J. Environ. Radioact., 1992, 17, 49.

41 H. Funaki, H. Hagiwara and T. Tsuruta, The behaviour of radiocesium deposited in an upland reservoir after the Fukushima Nuclear Power Plant accident, Symposium NW - Scientific Basis for Nuclear Waste Management XXXVII, Mater. Res. Soc. Symp. Proc., 2014, 1665, 165.

42 T. Tsuruta, H. Harada, T. Misonou, T. Matsuoka and Y. Hodotsuka, Horizontal and vertical distributions of ${ }^{137} \mathrm{Cs}$ in seabed sediments around the river mouth near Fukushima Daiichi Nuclear Power Plant, J. Oceanogr., 2017, 73, 547.

43 Y. Koibuchi, M. Murakami, K. Sueki and Y. Onda, Sedimentassociated radiocesium originated from Fukushima Daichi Nuclear Power Plant flowing from Ohori river to Lake Taganuma, J. Water Environ. Technol., 2015, 13, 249.

44 K. Yoshimura, Y. Onda and T. Fukushima, Sediment particle size and initial radiocesium accumulation in ponds 
following the Fukushima DNPP accident, Sci. Rep., 2014, 4, 450.

$45 \mathrm{~K}$. Yoshimura, Y. Onda and H. Kato, Evaluation of radiocesium wash-off by soil erosion from various land uses using USLE plots, J. Environ. Radioact, 2015, 139, 362.

46 D. E. Walling and H. Qingping, Interpretation of cesium-137 profiles in lacustrine and other sediments: the role of catchment-derived inputs, Hydrobiologia, 1992, 235, 219.

47 S. Iwagami, Y. Onda, W. Sakashita, M. Tsujimura, Y. Satou, R. Konuma, M. Nishino and Y. Abe, Six-year monitoring study of ${ }^{137} \mathrm{Cs}$ discharge from headwater catchments after the Fukushima Daiichi Nuclear Power Plant accident, $J$. Environ. Radioact., 2019, 210, 106001.
48 Japanese Ministry of the Environment, FY2014 Decontamination Report - A Compilation of Experiences to Date on Decontamination for the Living Environment Conducted by the Ministry of the Environment - (Tentative translation), 2015.

49 Japanese Ministry of the Environment, http:// josen.env.go.jp/en/decontamination/, (accessed 5 June 2020).

50 J. Särkkä, A. Keskitalo and A. Luukko, Temporal changes in concentration of radiocesium in lake sediment and fish of southern Finland as related to environmental factors, Sci. Total Environ., 1996, 191, 125. 